\title{
Ideological Change Research on Political Ideology Education of the Party Members Based on Fuzzy Analytic Hierarchy Process
}

\author{
DU Lunfang ${ }^{1, \text { a }}$ \\ ${ }^{1}$ Wuhan university of technology, Wuhan 430223 , China \\ a dulunfang@yeah.net
}

Keywords: Ideology, Party member, Advancement, Fuzzy analytic hierarchy process, Model

\begin{abstract}
In recent years, ideological change becomes a very important aspect of national historic vicissitudes. The education which about party members' political ideology has drew more and more attention, and it plays a very important role in ideological change of the party members. Their ideological change directly relates to the advancement or some other aspects of party members, so it is necessary to research on this field. The fuzzy analytic hierarchy process is adapted to research on political ideology education of the Party members in this paper, and it uses the infrequent modeling method to do a research into this field. It bases on the model and data to do an ideological change research on political ideology education of the Party members thoroughly, the study of this aspect has an important significance for the ideological change.
\end{abstract}

\section{Introduction}

At present, ideological change is an inevitable requirement of the transformation of socialist society, and it has very important realistic meanings for the smooth transformation of economic society and the construction of a well-off society. The one of the emphasis is about the ideological change of the Party members' political ideology education. This paper makes a relative research that based on the fuzzy analytic hierarchy process $[1,2]$.

\section{Basic principles of the Fuzzy Analytic Hierarchy Process}

To describe the basic principles of fuzzy analytic hierarchy process, first we have the following description of fuzzy consistent matrix with fuzzy analysis method [3,4]: When $\mathrm{k}$ is arbitrary, $r_{i j}=r_{i k}-r_{j k}+0.5$ is tenable, then the fuzzy judgment matrix that formed $R=\left(r_{i j}\right)_{m \times m}$ belongs to fuzzy consistent matrix. About the fuzzy consistent matrix which formed $R=\left(r_{i j}\right)_{m \times m}$, it has four properties as follow: First, the fuzzy consistent matrix $\mathrm{R}$ exists $r_{i j} \equiv 0.5$; Second, the arbitrary sub matrix of fuzzy consistent matrix $\mathrm{R}$ belongs to fuzzy consistent matrix; Third, in the fuzzy consistent matrix $\mathrm{R}$, line $\mathrm{i}$ elements plus row $\mathrm{i}$ elements equal $\mathrm{m}$. Forth, there are properties of center-division transitivity in the fuzzy consistent matrix R. The fuzzy complementary matrix can be obtained and be summed, that is:

$$
r_{i}=\sum_{j=1}^{m} r_{i j}, i=1,2, \ldots \ldots, m
$$

Then make a mathematic transformation, the formula shown as follow:

$$
a_{i j}=\frac{r_{i}-r_{j}}{2 m}+0.5
$$

According to the above description, it can be known that matrix $A=\left(a_{i j}\right)_{m \times m}$ belongs to fuzzy consistent matrix. Based on synthesizing above, some descriptions about the fuzzy consistent matrix are obtained as follow: As for the fuzzy consistent matrix of $R^{l}=\left(r_{i j}^{l}\right)_{m \times m}(l=1, \ldots \ldots, n)$, 
when $r_{i j}=\sum_{i=1}^{n} w l r_{i j}^{l}, \sum_{i=1}^{n} w l=1$, then $R^{l}=\left(r_{i j}^{l}\right)_{m \times m}$ was composed by n matrix.

\section{Build the relation matrix of Party members' ideological change}

This paper firstly builds related characteristics set which about the current Party ideological change $Q=\left\{O_{1}, O_{2}, \ldots \ldots, O_{k}\right\}(k=1, \ldots \ldots, n)$, while according to the difference of membership degree and fuzzy number, to build a change relation matrix of feature set for the current change relation of their ideological features, as shown below [5]:

$$
A=\left(a_{i j}\right)_{m \times m}
$$

At the same time, $a_{i j}=1.0$, it represents that feature element $\mathrm{O}_{\mathrm{i}}$ is more important than $\mathrm{O}_{\mathrm{j}}$; $a_{i j}=0.5$, then it represents that they are the same important; when $a_{i j}=0.0$, it is on the contrary.

\section{Build the change relation matrix of Party members' political ideology education}

Due to this paper researched on the ideological change of the political ideology education of Party members, it must be compared with that under other circumstances, it is a multiobjective decisionmaking problem, and through above that $\mathrm{n}$ fuzzy change relational matrix can be obtained.

$$
\mathrm{B}^{l}=\left(b_{i j}^{k}\right)_{m \times m}(k=1, \ldots . ., n)
$$

According to the last part, it can be known that when $b_{i j}^{k}=1.0, \mathrm{~T}_{\mathrm{i}}$ is better than $\mathrm{T}_{\mathrm{j}}$; when $b_{i j}^{k}=0.5$, Ti is as good as $\mathrm{T}_{\mathrm{j}}$; when $b_{i j}^{k}=0.0, \mathrm{~T}_{\mathrm{j}}$ is better than $\mathrm{T}_{\mathrm{i}}$ 。

\section{Fuzzy consistent matrix}

Transform the change relation matrix $A=\left(a_{i j}\right)_{m \times m}$ and $\mathrm{B}^{l}=\left(b_{i j}^{k}\right)_{m \times m}(k=1, \ldots \ldots, n)$, they become fuzzy consistent matrix. When $R^{0}=\left(r_{i j}^{0}\right)_{n \times n}$, there is $r_{i j}^{0}=\frac{r_{i}-r_{j}}{2 n}+0.5, r_{i}=\sum_{j=1}^{n} a_{i j}$; When $R^{\mathrm{k}}=\left(r_{i j}^{k}\right)_{m \times m}$, there is $r_{i j}^{\mathrm{k}}=\frac{r_{i}-r_{j}}{2 m}+0.5, r_{i}=\sum_{j=1}^{m} b_{i j}^{k}$

\section{Under normal circumstances, the single ideological change of the Party members}

This paper calculates the reform value $s_{i}^{k}$ when the ideology $\mathrm{T}_{\mathrm{i}}$ under the feature Ok, the formula shown as follow $s_{i}^{k}=\frac{\bar{s}_{i}}{\sum_{j=1}^{m} s_{j}}$, there is $\bar{s}_{i}=\left(\prod_{j=1}^{m} r_{i j}^{k}\right)^{1 / m}$, and $\sum_{i=1}^{m} s_{i}^{k}=1$, the larger value $\mathrm{s}_{i}^{k}$ becomes, the higher change degree it represents. According to the above, use the root method to calculate the weight $\mathrm{W}_{\mathrm{k}}$.

\section{Party members' ideological change of political ideology education}

Based on the last part, calculate the overall change value Vt of Party members ideological change, the formula shown as follow 


$$
V_{t}=\sum_{k=1}^{n} w_{k} s_{i}^{k}
$$

According to the size of Vt to study the Party members ideological change of political ideology education.

\section{Ideological change research on political ideology education of the Party members based on fuzzy analytic hierarchy process}

We make the use of the fuzzy transform principle to synthesize each index.

(1) Determining the factors field of the evaluation object evaluation index: $u=\left\{u_{1}, u_{2}, \cdots \cdots, u_{p}\right\}$, at the beginning of the investigation of the Party menbers service quality to customers, the Party menbers can Unified design out the service contents of the quality problems and ask method, assigning the competent department for unified training.

(2) Determining the comments field level $v=\left\{v_{1}, v_{2}, \cdots \cdots, v_{p}\right\}$, that is level set, Each level can correspond to one fuzzy subset.it can take the necessary measures to induce and stimulate the customer to actively participate in evaluation,so that it can keep continuous measurement of continuity.

(3) To establish fuzzy relation matrix $R$

After optimizing the Political ideology education of the Party members service quality evaluation system, it needs to quantify the appraised things from every factors $u_{i}(i=1,2, \cdots \cdots, p)$, determining the grade fuzzy subset of membership from single factor $\left(R \mid u_{i}\right)$, and then getting the fuzzy relation matrix:

$$
R=\left[\begin{array}{cc}
R \mid & u_{1} \\
R \mid & u_{2} \\
\cdots & \\
R \mid & u_{p}
\end{array}\right]=\left[\begin{array}{cccc}
r_{11} & r_{12} & \cdots & r_{1 m} \\
r_{21} & r_{22} & \cdots & r_{2 m} \\
\cdots & \cdots & \cdots & \cdots \\
r_{p 1} & r_{p 2} & \cdots & r_{p m}
\end{array}\right]_{p . m}
$$

The $\mathrm{i}$ line of the $\mathrm{R}$ matrix in the $\mathrm{j}$ column element,sugests that the grade fuzzy subset of membership from single factor .A appraised thing in certain $u_{i}$ factors' performance is depicted by the fuzzy vector $\left(R \mid u_{i}\right)=\left(r_{i 1}, r_{i 2}, \cdots \cdots, r_{i m}\right)$. At the same time the Party menbers should add the managers of the service quality "dark review" to avoid the inveracious effect of the public investigation. While in other evaluation methods, it is more described by a actual value index ,so it requires more information from the point of view of fuzzy comprehensive evaluation .

(4) Determining the evaluation factors of the weight vector

In the fuzzy comprehensive evaluation, it determines the evaluation factors of the weight vector: $A=\left(a_{1}, a_{2}, \cdots \cdots, a_{p}\right)$. The elements $a_{i}$ in the weight vector A is essentially factors $u_{i}$ on fuzzy membership . This article used analytic hierarchy process (AHP) to determine evaluation index among the relative importance order. Department management organise s corresponding training, leting employees know the third party evaluation form, content, so as to determine weight coefficient, and synthetic before the normalization, it is:

$$
\sum_{i=1}^{p} a_{i}=1, a_{i} \geq 0, i=1,2, \cdots \cdots, n
$$

(5) The results vector of synthetic fuzzy comprehensive evaluation

By using the appropriate operator A,we can synthesize the appraised thing to get the fuzzy comprehensive evaluation result of the vector of the appraised thing B . The Party menberss strengthen 
the related communication with a third party to guide the third party having the correct and effective evaluation on Party menbers service quality. At the same time, it should make the third party assessment as a reference between a customer evaluation and Party menbers organization evaluation .The customer evaluation and Party menbers organization evaluation in the execution process according to the third party assessment way and content to improve itself, thus it can get more objective service quality evaluation.it is as below:

$$
A \circ R=\left(a_{1}, a_{2}, \cdots \cdots, a_{p}\right)\left[\begin{array}{cccc}
r_{11} & r_{12} & \cdots & r_{1 m} \\
r_{21} & r_{22} & \cdots & r_{2 m} \\
\cdots & \cdots & \cdots & \cdots \\
r_{p 1} & r_{p 2} & \cdots & r_{p m}
\end{array}\right]=\left(b_{1}, b_{2}, \cdots \cdots, b_{m}\right)=B
$$

Among them, ${ }^{b_{1}}$ is composed of the $\mathrm{J}$ column operation between A and $\mathrm{R}$. It shows on the whole the appraised thing on the level fuzzy subset of the degree of membership. Completing appraisal report, in order to reflect the result of assessment, and let the appraisal report as the bases of Party menbers quality management results and staff rewards and punishment for promotion .

\section{Conclusion}

From the perspective of fuzzy analytic hierarchy process, this Paper researched on the issues of the ideological change of Party members' political ideology education. In the education of Party members' advancement, it determined the height of their political ideology education, which had a great influence on the current ideological change of party member. Papers used to adopt modeling method to study this kind of problem, however in this study is hardly to be seen, its research method has some reference significance to similar problems. And it is about the ideological change of the Party members' political ideology education which played an important role to the ideological change.

\section{References}

[1] Wataru Koyama, "Honorifics in critical-historic pragmatics: the linguistic ideologies of modernity, the national standard, and modern Japanese honorifics", Journal of Pragmatics, Vol. 36, No. 11, pp. 2023-2054, 2006.

[2] Darel E. Paul, "World cities as hegemonic projects: the politics of global imagineering in Montreal", Political Geography, Vol. 23, No. 5, pp. 571-596, 2005.

[3] Samuel T. Hunter, Katrina E. Bedell-Avers, Michael D. Mumford, "Impact of situational framing and complexity on charismatic, ideological and pragmatic leaders: Investigation using a computer simulation", The Leadership Quarterly, Vol. 20, No. 3, pp. 383-404, 2009.

[4] CHEN Feng, "The Study on ERP System Evaluation Based on Fuzzy Analytic Hierarchy Process Method", JDCTA, Vol. 6, No. 22, pp. 231 - 238, 2012.

[5] Clem Brooks, Catherine Bolzendahl, "The transformation of US gender role attitudes: cohort replacement, social-structural change, and ideological learning", Social Science Research, Vol. 33, No. 1, pp. 106-133, 2005. 